\title{
Sistemas de polonização de duas espécies simpátricas de Dalechampia (Euphorbiaceae) no Amazonas, Brasil (")
}

\begin{abstract}
Resumo
Dalechampia affinis (Euphorbiaceae) e D. scandens crescem simpatricamente nos arredores de Manaus, Amazonas, Brasil. Durante uma pesquisa, realizada em setembro de 1978, observou-se que as duas espécies diferiam uma da outra no tamanho da glândula floral que secreta resina (o atrativo do polinizador), na disposição das flores estaminadas e pistiladas na inflorescência, e no período do dia que as brácteas da infiorescência se abrem. Tais diferenças resultam de ser D. affinis polinizada principalmente por Euglossa (Apidae) e D. scandens principalmente por Hypanthidium (Megachilidae). Como uma conseqüência dessas diferenças há, provavelmente, pouco fluxo de pólen entre as duas espécies observadas.
\end{abstract}

O gênero Dalechampia (Euphorbiaceae) tem cerca de 100 espécies, das quais a maioria é Sul-americana. Todas as espécies de Dalechampia ocorrem em comunidades tropicais de baixa e média elevação. A maioria das espécies é trepadeira, embora algumas espécies neotropicais sejam arbustos (Pax \& Hoffmann, 1919) .

As flores de Dalechampia são unissexuais mas são agregadas em inflorescências pseudoantiais que funcionam como flores bissexuais. Duas brácteas ạue são geralmente grandes e vistosas, abrigam três flores pistiladas e usualmente 9 ou 10 flores estaminadas. Acima das flores estaminadas, há um cacho de bractéolas que funciona como uma glândula, secretando o atrativo do polinizador (Webster \& Webster , 1972) .

O atrativo do polinizador produzido pela maioria das espécies de Dalechampia é uma resina triterpenóide (Armbruster \& Seigler, $\mathrm{s} / \mathrm{d}$ ), que é coletada por abelhas fêmeas (ou operárias) que empregam o material na construção do ninho. As abelhas efetuam a polini-

\author{
W. Scott Armbruster ("म) \\ G. L. Webster ("*)
}

zaçãc durante a coleta de resina (Webster \& Armbruster, 1977; Armbruster \& Webster, 1979). Abelhas dos gêneros Hypanthidium (Megachilidae). Euglossa, Eulaema, Euplusia, e Trigona (todas Apidae), têm sido registradas como coletoras de resina de Dalechampia (Mülier, 1879; Cammerloher, 1931; Webster \& Armbruster, 1977; Armbruster \& Webster, 1979; Armbruster, ined.). A resina secretada por Dalechampia pode ser coletada de plantas silvadas a relativamente grandes distâncias, por abelhas Euglossinae (incluindo Euglossa, Eulaema e Euplusia) em um padrão de "traplining" (Janzen, 1971; Armbruster \& Webster, 1979; Armbruster, ined.). Esta resina pode ser proveitosa na construção do ninho destas abeIhas tropicais que são importantes polinizadoras de muitas outras plantas tropicais.

Todas as Dalechampia que foram por nós testadas são autocompatíveis e são capazes de, pelo menos, ocasional auto-polinização (Armbruster, ined.). A maioria das espécies, contudo, é efetivamente protogínica; as flores pistiladas estão receptívas de um a vários dias antes da abertura das primeiras flores estaminadas; durante este período somente polinização cruzada é possível. Subseqüente ao período pistilado, há um período bissexual, durante o qual as flores pistiladas estão ainda receptivas e as flores estaminadas se abrem e liberam pólen. Auto-polinização pode ocorrer durante esta fase.

\section{MATERIAL E MÉTODOS}

Fizemos observações em duas espécies simpátricas de Dalechampia, D. affinis Müll. Arg. e D. scandens L., próximo da vila de Ca-

(*) - Este estudo foi financiado pela bolsa do NSF DEB 77-24263 (U.S.A.).

(") - Department of Botany, University of California, Davis, CA 95616, U.S.A. 
cau Pirera, do outro lado do rio Negro, saindo de Nianaus. As plantas cresciam em baixa capceira secundária, ao longo das margens de uma estrada pavimentada. Nossas observações foram feitas de 10 a 25 de setembro de 1978.

Neste local de estudo, localizamos uma área onde ambas $D$. affinis e $D$. scandens eram comuns, florescendo em abundância, e ocorriam próximas uma da outra. Durante cinco dias, não consecutivos, num total de ca. de 20 horas de observação, registramos o comportamento e movimento de todos os visitantes florais de ambas as espécies de Dalechampia. Também fizemos medidas das inflorescências de Dalechampia, anotando as dimensões importantes para os sistemas de polinização (Tab. 1). Amostras dos polinizadores foram coletadas e estão depositadas no Museu de Entomologia, Universidade de California, Davis, CA. USA.

\section{RESULTADOS}

Dalechampia affinis e D. scandens diferem marcadamente no tamanho da inflorescência e em certas características importantes da disposição das flores estaminadas e pistiladas. Estes diados estão apresentados na Tabela 1. $D$. affinis possui grandes brácteas brancas (ca. $40 \mathrm{~mm}$ ), uma grande glândula secretora de resina, e as anteras e estigmas estão localizadas relativamente longe da glândula de resina. Por outro lado, $D$. scandens possui brácteas de cor verde clara, muito menores (ca. $15 \mathrm{~mm}$ ), uma glândula de resina menor, e as anteras e estig- mas estão muito mais próximas da glândula de resina. Os estigmas encontram-se muito mais próximos das anteras em $D$. scandens do que das de $D$. affinis.

As inflorescências de $D$. affinis permanecem na condição pistiladá ca. de dois dias e na condição bissexual ca. de 5-6 dias. Contudo, diferente da maioria das espécies de Dalechampiá e outras populações de D. scandens que têm sido estudadas, as inflorescências de $D$. scandens observadas na área de Manaus não mostraram a visual condição pistilada inicial. A primeira flor estaminada se abre no primeiro dia da antese pseudantial. As inflorescências permanecem na condição bissexual ca. de 5-6 dias.

Como na maioria das espécies de Dalechampia as brácteas de ambas, $D$. affinis e $D$. scandens, abrem e fecham em ciclos diurnos. Enquanto as brácteas estão fechadas, a resina e as flores estão inacessiveis aos insetos. As brácteas de $D$. affinis se abrem no meio da tarde (ca. 14,30-16,00 h) e começam a fechar ao entardecer (ca. 18,00 h.). Contudo, em D. scandens as brácteas se abrem por volta das $10,3 \mathrm{C}-11,00 \mathrm{~h}$ e permanecem abertas até $\mathrm{ca}$. $18,00 \mathrm{~h}$, quando começam a fechar.

D. affinis é visitada por abelhas fêmeas, de tamanho médio, do gênero Euglossa (Euglossini. Apidae), que começam as visitas ca. $14,3 \mathrm{C} \mathrm{h}$ e usualmente coletam resina (em pou$\cos$ casos, observamos Euglossa coletando pólen de Dalechampia). Quando está coletando resina, esta abelha toca os estigmas das inflorescências na condição pistilada e usual-

TABELA 1 - Dimensões das inflorescências e visitantes florais de Dalechampia, Manaus, Brasil, setembro 1978

\begin{tabular}{|c|c|c|c|c|c|c|}
\hline & $\begin{array}{c}\text { Area média da } \\
\text { glândula } \\
\left(\mathrm{mm}^{2}\right)\end{array}$ & $\begin{array}{l}\text { Distância média } \\
\text { estigma-glândula } \\
\text { (mm) }\end{array}$ & $\begin{array}{l}\text { Distância média } \\
\text { antera-glândula } \\
\text { (mm) }\end{array}$ & $\begin{array}{l}\text { Distância média } \\
\text { antera-estigma } \\
(\mathrm{mm})\end{array}$ & $\begin{array}{c}\text { Visitante floral } \\
\text { (tamanho em mm) }\end{array}$ & $\begin{array}{l}\text { Polinizador } \\
\text { efetivo }\end{array}$ \\
\hline \multirow[t]{2}{*}{$\begin{array}{l}\text { Dalechampia } \\
\text { affinis }\end{array}$} & 20.0 & 6.0 & 7.0 & 3.0 & $\begin{array}{l}\text { Euglossa } \\
\text { sp. (11) }\end{array}$ & + \\
\hline & & & & & $\begin{array}{l}\text { Hypanthidium } \\
\text { aff. melanopterum (7) }\end{array}$ & - \\
\hline $\begin{array}{l}\text { Dalechampia } \\
\text { scandens }\end{array}$ & 7.0 & 3.0 & 2.8 & 1.0 & $\begin{array}{l}\text { Hypanthidium } \\
\text { aff. melanopterum (7) }\end{array}$ & + \\
\hline
\end{tabular}


mente só as anteras das inflorescências na condição bissexual. Desta maneira, aparentemente, o pólen é transferido das flores estaminadas das inflorescências na condição bissexual para os estigmas das inflorescências, na condição pistilada.

D. affinis é também visitada por fêmeas de Hypanthidium aff. melanopterum Cockerell (Megachilidae), uma abelha muito menor (Tabela 1, fig. 3). Esta abelha coleta tanto resina como pólen, mas não toca os estigmas. Por isto, raramente, alguma vez, realiza-se polinização nesta espécie de Dalechampia.

D. scandens também é visitada pelas mesmas espécies (e mesmos indivíduos) de $\mathrm{Hy}$ panthidium (fêmeas) coletando resina e/ou pólen das inflorescências. Como os estigmas estăo localizados relativamente próximo da glândula, a abelha toca os estigmas e efetua a polinização. Em nenhum caso, observamos Euglossa visitando D. scandens para coletar resina, embora, em uma ocasião, tenhamos observado uma Euglossa coletar pólen de três inflorescências de $D$. scandens.

\section{DISCUSSÃO}

Parece, à primeira vista, surpreendente que Euglossa fosse vista coletando resina somente de $D$. affinis, considerando que tanto $D$. affinis como $D$. scandens secretam resinas semelhantes e Hypanthidium coleta resina de ambas as espécies. Aparentemente Euglossa está "selecionando" somente as inflorescências que têm grandes quantidades de resina (i.e. D. affinis) e "ignoram" as inflorescências que têm menores quantidades de resina (i.e. D. scandens). Euglossa é uma abelha razoavelmente grande $(11 \mathrm{~mm})$; ela pode levar reiativamente grandes cargas de resina na sua corbicula, uma quantidade de resina maior do que geralmente é disponivel em uma inflorescência. Em Cacau Pirera, observamos Euglossa coletar resina de, em média, 3,3 inflorescências ( $N=9$; amplitude: $1-7)$ por viagem. Uma vez que estas abelhas coletam grandes quantidades de resina de algumas e muitas inflorescências, pode ser energeticamente vantajoso Euglossa limitar suas atividades de coleta de resina para inflorescências que possuem grandes quantidades de resina (cf. discussão relacionada com a coleta de néctar em Heinrich \& Raven, 1972).

Por outro lado, Hypanthidium é uma abeIha muito menor e não pode transportar tanta resina como Euglossa. Como outros Megachilidae, Hypanthidium não possui corbícula tibial; em vez disto, ela carrega materiais na escopa abdominal. A escopa é composta de densos cachos de pêlos e, conseqüentemente, é inadequada para carregar resinas pegajosas; somente pólen.

Hypanthidium carrega resina sob a forma de um pequeno glóbulo atrás das mandíbulas. Ela é incapaz de carregar tanta resina como uma abelha de tamanho semelhante pode carregar em suas pernas traseiras (eg. Trigona). Assim, por causa de suas restrições morfológicas e de tamanho, Hypanthidium é incapaz de transportar tanta resina como Euglossa; de fato, elas têm sido observadas carregando menos de cerca de $1 / 10$ da resina de Euglossa (Armbruster, ined.). Por isso, provavelmente, não há vantagem para Hypanthidium restringir suas coletas de resina a espécies de glândulas grandes.

Um fator adicional a ser considerado é que freqüentemente Hypanthidium coleta pólen nas mesinas visitas em que coleta resina. Uma abelha forrageira pode "dar-se ao luxo" de coletar pequenas quantidades de resina em cada inflorescência, porque ela está "tirando proveito" da coleta de pólen ao mesmo tempo.

Embora Hypanthidium visite ambas as espécies de Dalechampia, ela raramente toca os estigmas de $D$. affinis. Conseqüentemente $D$. affinis é polinizada somente por Euglossa e não está sujeita à contaminação por pólen de D. scandens.

D. scandens pode estar sujeita a algum fluxo de pólen de $D$. affinis uma vez que $\mathrm{Hy}$ panthidium pega pólen de ambas as espécies e aparentemente deposita pólen nos estigmas de $D$. scandens. Contudo, a contaminação do estigma de $D$. scandens por pólen de $D$. affinis deve ser relativamente baixa, porque as brácteas de $D$. scandens abrem muito mais cedo do que as brácteas de $D$. affinis. Noventa por 


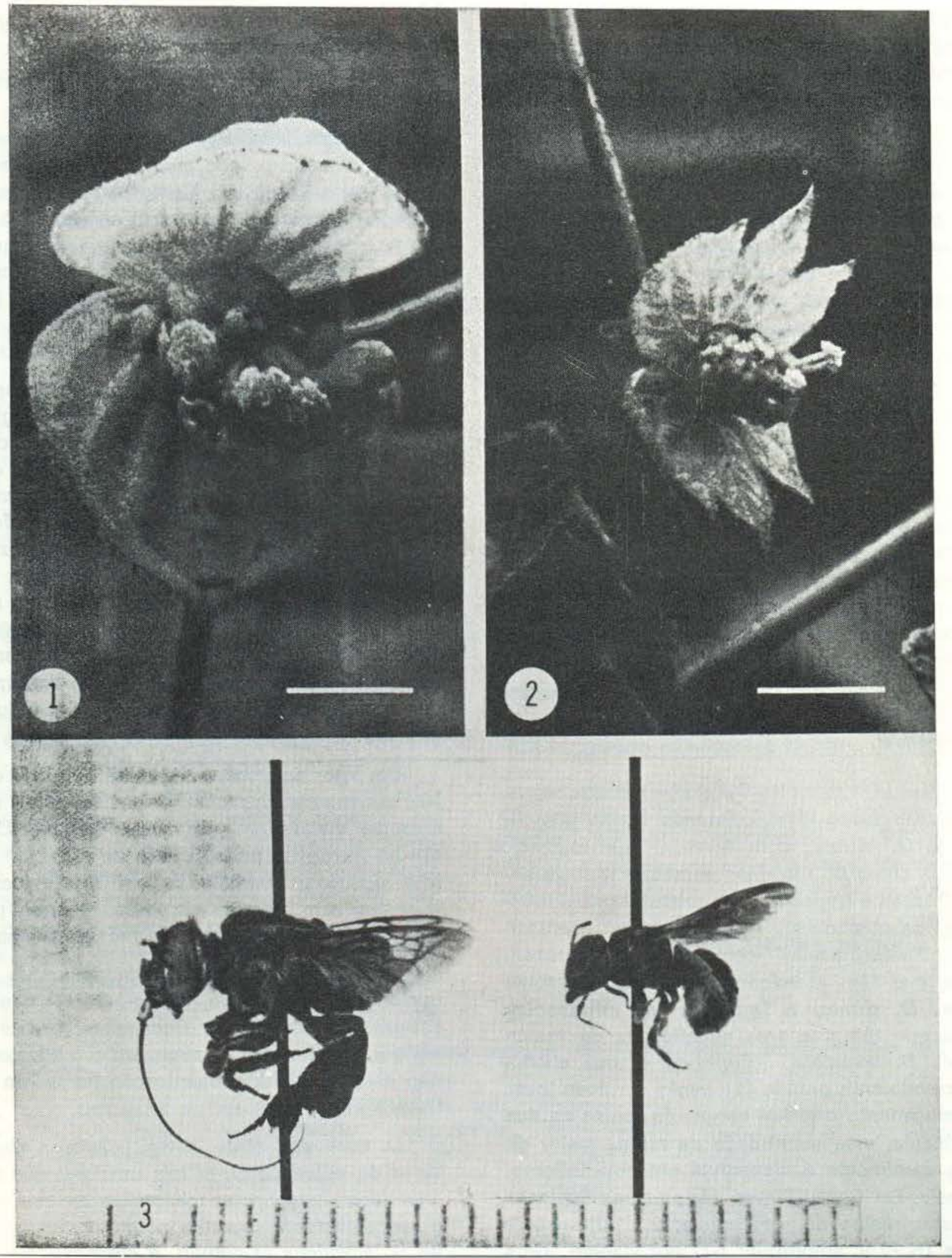

Figs. 1-3 - Dalechampia affinis, D. scandens e polinizadores. (As linhas nas figuras 1 e 2 representam $1 \mathrm{~cm}$. A régua, na figura 3 , está graduada em milímetros): 1) - Dalechampia affinis, inflorescência em condição bissexual. Note a grande glândula, 3 flores estaminadas abertas e 3 grandes estigmas; 2) - Dalechampia scandens, inflorescência em condição bissexual. Note a pequena glândula, 5 flores estaminadas abertas e 3 flores pistiladas; 3 ) - 0 polinizador de D. affinis, Euglossa sp. (esquerda), e o polinizador de D. scandens, Hypanthidium aff. melanopterum (direita). 
cento $(\mathrm{N}=26)$ das visitas observadas de Hypanthidium em D. scandens ocorreram durante as 3,5 horas antes da abertura das inflorescências de $D$. affinis, um período no qual Hypanthidium tem que carregar predominantemente cargas de pólen puro de $D$. scandens.

Dalechampia affinis e D. scandens, embora simpátricas nos arredores de Manaus, aparentemente possuem fluxos de pólen parcialmente segregados. Esta segregação consiste no fato de $D$. affinis "utiliizar" polinizadores diferentes dos $D$. scandens e porque $D$. scandens abre suas brácteas mais cedo que $D$. affinis.

\section{AGRADECIMENTOS}

Desejamos agradecer aos Drs. Norman D. Penny, William Rodrigues e a outros funcionários do INPA por sua cooperação e assistência.

\section{SUMMARY}

During September, 1978 observation were made near Cacau Pirêra, in the vicinity of Manaus, Amazonas, Brazil, on the pollination systems of two sympatric species of Dalechampia (Euphorbiaceae). The flowers of Dalechampia are unisexual; three pistillate arid usually 9-10 staminate flowers are aggregated int? 3 functionally bisexual inflorescence which is subtended by two large showy bracts. The two sympatric species which occur near Manaus, D. affinis and D. scandens differ from each other in time of day that the inflorescences are open for pollination, size of bracts, the distances from the flowers to the gland which secretes resin (the pollinator attractant), and the amount of resin secreted. D. affinis secretes a larger amount of resin than D. scandens, attracting Euglossa sp. and Hypanthidium $\mathrm{nr}$. melanopterum. Because the distance between the gland and stigma is relatively great, only the larger bee, Euglossa, pollinates D. affinis. D. scandens secretes a smaller amount of resin and attracts only small bees, Hypanthidium $\mathrm{nr}$. melanopterum, which do pollinate this small-flowered species. The attraction of different bees by such similar piant species is probably the result of the tendency for the larger bees i.e. Euglossa) to forage resin only from sources with large amounts of resin, "ignoring" inflorescences with small amounts of resin. Although both D. affinis and D. scandens are visited by Hypanthidium, the pollen flow between the two species is probably fairly low. Hypanthidium poilinates D. scandens early in the day before the inflorescences of $\mathbf{D}$. affinis are open. It is too small a bee to transfer any pollen to the stigmas of D. affinis when inflorescences of that species are open in the late afternoon.

\section{REFERÊNCIAS BIBLIOGRÁFICAS}

Armbruster, W.S. \& Webster, G.L.

1979 - Pollination of two species of Dalechampia (Euphorbiaceae) in Mexico by euglossine bees. Biotropica, 11: 278-283.

CAMmerloher, H.

1931 - Blütenbiologie 1. Gebrüder Borntraeger, Berlin.

HeinRich, B. \& Raven, P.H.

1972 - Energetics and pollination ecology. Science, 176: $597-602$.

JANZEN, D.H.

1971 - Englossine bees as long-distance pollinators of plants. Science, 171: 203-205.

MÜLleR, $\mathrm{H}$.

1879 - Die Wechselbeziehungen zwischen den Blumen und den ihre Kreuzung vermittelnden Insekten. In: Schenck, Handbuch der Botanik I. Eduard Trewent, Breslau. p. 1-112.

PAX, F. \& HoFfmanN, K.

1919 - Euphorbiaceae-Dalechampieae. Das Pflanzenreich, IV, 147, 12 (68): p. 1-59.

WEBSTER, G.L. \& ARMBruster, W.S.

1977 - Pollination ecology of some species of Dalechampia in Mexico. Bot. Soc. Amer. Misc. Publ., 154: 71.

Webster, G.L. \& Webster, B.D.

1972 - The morphology and relationships of Dalechampia scandens (Euphorbiaceae). Amer. J. Bot., 59: 573-586

(Aceito para publicação em 19/06/80) 